\title{
The Sensitivity of Computerized Tomography in Diagnosis of Brain Astrocytomas
}

\author{
E. Abd Elrahim1,2, A. Elzaki 1,2, Ali Hassan1, A. M. Abd Elgyoum ${ }^{1,3}$, H. Osman ${ }^{1,4}$ \\ ${ }^{1}$ College of Applied Medical Science, Taif University, Taif, Saudi Arabia \\ ${ }^{2}$ Faculty of Radiology Science and Medical Imaging, Alzaiem Alazhari University, Khartoum, Sudan \\ ${ }^{3}$ National Ribat University, Khartoum, Sudan \\ ${ }^{4}$ College of Medical Radiologic Science, Sudan University of Science and Technology, Khartoum, Sudan \\ Email: sawham40@yahoo.com, rashidrahim1976@yahoo.com
}

Received 12 September 2014; revised 10 October 2014; accepted 8 November 2014

Copyright (C) 2014 by authors and Scientific Research Publishing Inc.

This work is licensed under the Creative Commons Attribution International License (CC BY).

http://creativecommons.org/licenses/by/4.0/

c) (i) Open Access

\begin{abstract}
Astrocytomas are tumors that arise from astrocytes-star-shaped cells that make up the "glue-like" or supportive tissue of the brain. Astrocytomas can appear in various parts of the brain and nervous system, including the cerebellum, the cerebrum, the central areas of the brain, the brainstem and the spinal cord. The main objective of this study was to detect the sensitivity of the CT scan in diagnosis of the brain astrocytoma, in patients who were confirmed as brain gliomas using computerized tomography of the brain versus brain tissue biopsy after surgery. One hundred and one patients were included in this study. Bio-data collected for these patients (age, gender), radiographic appearance, contrast enhancement and the site of the tumor, were statistically analyzed. Out of the 101 patients with brain gliomas, $52(51.5 \%)$ were male whose ages ranged between 1 and 80 years, and $64(63.4 \%)$ cases were diagnosed as astrocytoma by CT. This study concluded that the CT brain was sensitive in the diagnosis of brain astrocytomas.
\end{abstract}

\section{Keywords}

CT, Brain, Gliomas, Sensitivity

\section{Introduction}

Astrocytomas are glial cell tumors that are derived from connective tissue cells called astrocytes. These cells can be found anywhere in the brain or spinal cord. Astrocytomas are the most common type of childhood brain tu-

How to cite this paper: Abd Elrahim, E., Elzaki, A., Hassan, A., Abd Elgyoum, A.M. and Osman, H. (2014) The Sensitivity of Computerized Tomography in Diagnosis of Brain Astrocytomas. Open Journal of Radiology, 4, 309-313.

http://dx.doi.org/10.4236/ojrad.2014.44040 
mor and the most common type of primary brain tumor in adults. Astrocytomas are generally subdivided into high-grade or low-grade tumors. High-grade astrocytomas are the most malignant of all brain tumors. Furthermore, astrocytomas are classified for presenting signs, symptoms, treatment and prognosis based on the location of the tumor. Patients usually have symptoms of increased intracranial pressure, headache, and vomiting also seizures, memory loss, and changes in behavior are the most common early symptoms of astrocytoma. Other symptoms may occur depending on the size and location of the tumor. There can also be problems with walking and coordination, as well as double vision. In adults, astrocytomas are more common in the cerebral hemispheres (cerebrum), where they commonly cause increased intracranial pressure (ICP), seizures, or changes in behavior [1]. See images in Figure 2. To obtain an accurate diagnosis, your doctor will begin with a neurological examination followed by an MRI or CT scan. The scan may be done with a contrast dye that makes the border and details of the tumor more visible. In tumor cases, the scan will help your doctor determine the size, location and probable type of tumors.

Some physicians may also request an MRS (magnetic resonance spectroscopy) scan which measures chemical and mineral levels in a tumor. Those measurements may give a suggestion as to whether a tumor is malignant or benign. It may also help distinguish a brain tumor from other medical problems, such as infection (tuberculosis, parasite, bacterial and fungus), demyelination (a disease that damages the myelin or protective sheath of a brain's neurons) or a stroke. On MRI with contrast, high grade gliomas show brightly (this is called enhancement).

The importance of this study is to test CT sensitivity in investigation of astrocytomas.

The main objective of this study is to detect the sensitivity of the CT scan in diagnosis of the brain gliomas.

\section{Material and Methods}

\subsection{CT Equipment}

A CT scan uses a sophisticated X-ray machine linked to a computer to produce detailed, two-dimensional images of the brain. A patient lies still on a movable table that is guided into what looks like an enormous doughnut where the images are taken. A special dye may be injected into the bloodstream after a few CT scans to help better distinguish tumors (CT angiogram). A CT scan is painless and generally takes less than 10 minutes [2] The machine used was CT-98 Siemens Emotion 16 CT Scanner, which was based on Siemens proprietary detector with $16 \times 0.6 \mathrm{~mm}$ and $8 \times 1.2 \mathrm{~mm}$ segments. It offers the acquisition of up to 16 slices per rotation in all sub-millimeter spiral acquisition modes for the clinical routine. With rotation times 1.5 sec for HeartView CT (optional), this canner is the entry point to ECG-gated, contrast-enhanced coronary imaging. SOMATOM Emotion minimizes the dose using the CARE Dose4D software that enables the achievement of the best diagnostic image quality at lowest possible dose, independent of patient size and anatomy. The mA are adjusted in realtime and so the software offers fully automated dose management with up to $68 \%$ dose reduction

\subsection{Sample Size}

There were 100 patients with different types of brain masses had been diagnosed as gliomas attended in neurosurgery department of Elshaab Teaching Hospital in Khartoum state. The sample had been selected randomly by the technique of non probability method. The study had been conducted from the period of 2009 up to 2012 . The data had been analyzed by statistically package for social sciences SPSS.

\subsection{Testing Protocol}

The patient lies supine on the scanning couch and is advanced towards the scanning field in the gantry. A scout image is generated by energizing the X-ray beam and passing the relevant part of the patient in one movement through the gantry. This continuous exposure as the patient moves through the beam generates a topogram which resembles a plain X-ray. In the case of the head, this is usually a lateral image of the skull. It is by nature a digital image and the windowing options already described can also be applied to it. From this scout image, the position number, and angulations of the subsequent slices are chosen. The axial plane is used most often for brain imaging. The axial plane offers the advantage of direct left to right comparison, which is useful in symmetrical structures like the head [3].

A biopsy is usually required to diagnose a brain tumor and confirm its type. In a biopsy, a tiny piece of tumor is removed for examination under a microscope. A biopsy can be performed separately or as part the surgery to 
remove the tumor [4].

\section{Results and Discussion}

From Table 1 and in study [5] which performed by Sanei et al., they studied the evaluation of CT Scan and MRI Findings of Pathologically Proved Gliomas in an Iranian Population, and the results were as follows; Among their patients, (60) (62.5\%) were male and (36) (37.5\%) were female [5]. So this study somewhat matched the results of Sanie et al. and this finding is somewhat agree with the current finding.

From Table 2 the results showed that the ages between (25-39 y middle age) registered high prevalence of brain astrocytoma which was common in this age as shown in study performed by Louis et al. [1] who confirmed that the astrocytoma is the most common type of primary brain tumor in the middle age.

In the diagnosis of 100 cases of brain glioma the CT scan diagnoses (64 patients) (63.4\%), and after the biopsy result confirmation the number of the patients decreased to (39 patients) (38.6\%) as in image in Figure 1 and Figure 2.

As in study (6) performed by Kendall et al. out of (13 patients) suffered from low grade astrocytomas (6 patients) $(0.46 \%)$. And the remaining 7 patients were the different type of gliomas [6]. This result agrees with my result.

In study which done by Bbadhe et al., they studied the brainstem gliomas-A clinicopathological for 45 cases with p53 immunohistochemistry, they concluded that diffuse astrocytomas were seen in 40 cases $(5 \%$ were Grade I, $47.5 \%$ Grade II, $32.5 \%$ Grade III and 15\% Grade IV) [7]. This result agrees with the current study result.

\begin{tabular}{ccc|}
\hline \multicolumn{2}{l}{ Table 1. Frequency distribution of patients according to the gender. } & \\
\hline Gender & Frequency & Percentage \\
\hline Male & 52 & $53.1 \%$ \\
Female & 48 & $46.9 \%$ \\
Total & 100 & $100 \%$ \\
\hline
\end{tabular}

Table 2. Frequency distribution of patients according to the age.

\begin{tabular}{ccc}
\hline Age Group (Years) & Frequency & Percent \\
\hline Less than 10 & 15 & 14.9 \\
$10-24$ & 15 & 14.9 \\
$25-39$ & 30 & 29.7 \\
$40-54$ & 24 & 23.8 \\
$55-70$ & 14 & 13.9 \\
Above 70 & 3 & 3.0 \\
Total & 101 & 100 \\
\hline
\end{tabular}

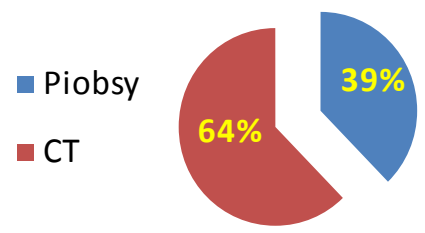

Figure 1. The diagnosis of brain astrocytoma by CT \& tissue biopsy. 
From Table 3 and in study [4] which was done by Butler, he studied the contrast enhanced CT scan and radionuclide brain scan in supratentorial gliomas, he found that; there was contrast enhancement in all 46 of the high grade gliomas (Kernohan's Grade Ill and IV). The index of contrast enhancement was moderate in 25 cases and marked in 21 cases and also agreed with the study [8].

Finally from Table 4, the study showed that the sensitivity of CT in the diagnosis of astrocytoma was $79 \%$, by using the equation of the sensitivity:

\section{Conclusion}

The study showed that the sensitivity of CT in the diagnosis of astrocytoma was $79 \%$. Male was common affected than female. The middle age was common affected age.

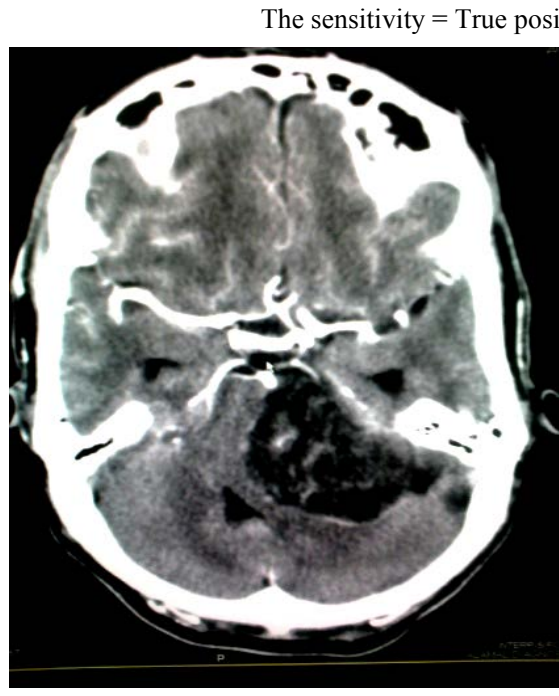

(a)

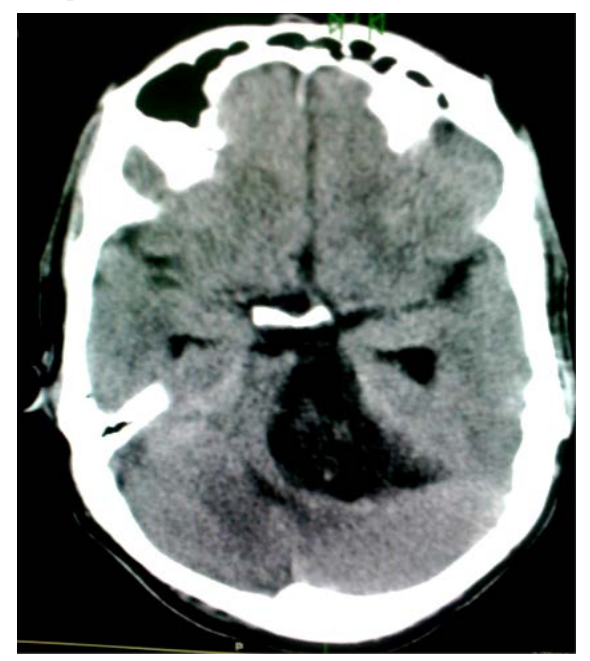

(b)

Figure 2. Axial CT brain images (b) without contrast and (a) with contrast showed a mixed lesion in the left cerebellar hemisphere crossing the midline with contrast enhancement. Astrocytoma.

Table 3. Relationship between the radio-density of the brain glioma and the contrast enhancement.

\begin{tabular}{ccccc}
\hline & \multicolumn{4}{c}{ Contrast Enhancement } \\
\hline \multirow{3}{*}{ Radiodensity } & Enhanced & Not Enhanced & Total \\
& Hyperdensic & 33 & 0 & 33 \\
& Hypodensic & 17 & 3 & 20 \\
& Mixed & 10 & 1 & 11 \\
& Total & 60 & 4 & 64 \\
\hline
\end{tabular}

Table 4. The test of the sensitivity.

\begin{tabular}{ccc}
\hline & Actual & \\
\hline Test & Positive & Negative \\
Positive & TP & FP \\
Negative & FN & TN \\
\hline
\end{tabular}

$\mathrm{TP}=$ true positive. 


\section{Recommendations}

Further studies were required to study the brain glioma and its etiology.

\section{Acknowledgements}

Authors would like to thank all staff of Al Shaab Teaching Hospital for their efforts during data collection phase.

\section{References}

[1] Malik, A.S., Boyko, O., Atkar, N. and Young, W.F. (2001) A Comparative Study of MR Imaging Profile of Titanium Pedicle Screws. Acta Radiologica, 42, 291-293. http://dx.doi.org/10.1080/028418501127346846

[2] Hu, T. and Desai, J.P. (2004) Soft-Tissue Material Properties under Large Deformation: Strain Rate Effect. Proceedings of the 26th Annual International Conference of the IEEE EMBS, San Francisco, 1-5 September 2004, 2758-2761.

[3] Ortega, R., Loria, A. and Kelly, R. (1995) A Semiglobally Stable Output Feedback PI2D Regulator for Robot Manipulators. IEEE Transactions on Automatic Control, 40, 1432-1436. http://dx.doi.org/10.1109/9.402235

[4] Wit, E. and McClure, J. (2004) Statistics for Microarrays: Design, Analysis, and Inference. 5th Edition, John Wiley \& Sons Ltd., Chichester.

[5] Prasad, A.S. (1982) Clinical and Biochemical Spectrum of Zinc Deficiency in Human Subjects. In: Prasad, A.S., Ed., Clinical, Biochemical and Nutritional Aspects of Trace Elements, Alan R. Liss, Inc., New York, 5-15.

[6] Giambastiani, B.M.S. (2007) Evoluzione Idrologica ed Idrogeologica Della Pineta di san Vitale (Ravenna). Ph.D. Thesis, Bologna University, Bologna.

[7] Wu, J.K. (1994) Two Problems of Computer Mechanics Program System. Proceedings of Finite Element Analysis and $C A D$, Peking University Press, Beijing, 9-15.

[8] Honeycutt, L. (1998) Communication and Design Course. http://dx.doi.org/10.1002/0470011084 
Scientific Research Publishing (SCIRP) is one of the largest Open Access journal publishers. It is currently publishing more than 200 open access, online, peer-reviewed journals covering a wide range of academic disciplines. SCIRP serves the worldwide academic communities and contributes to the progress and application of science with its publication.

Other selected journals from SCIRP are listed as below. Submit your manuscript to us via either submit@scirp.org or Online Submission Portal.
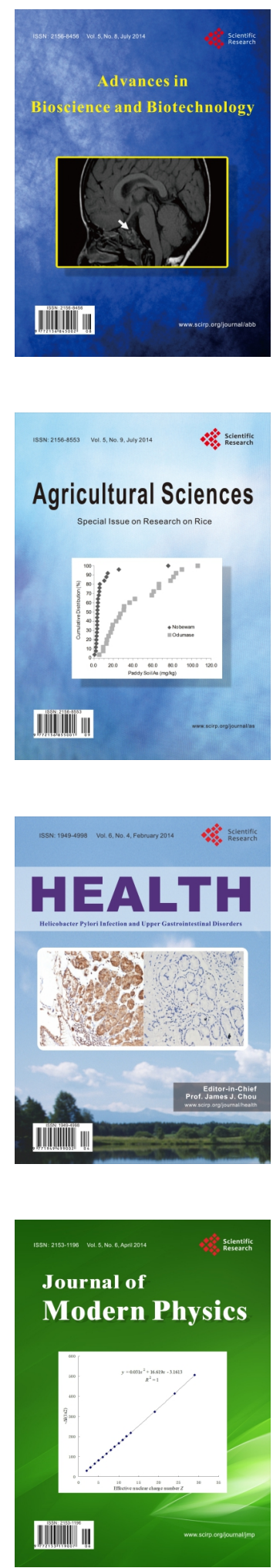
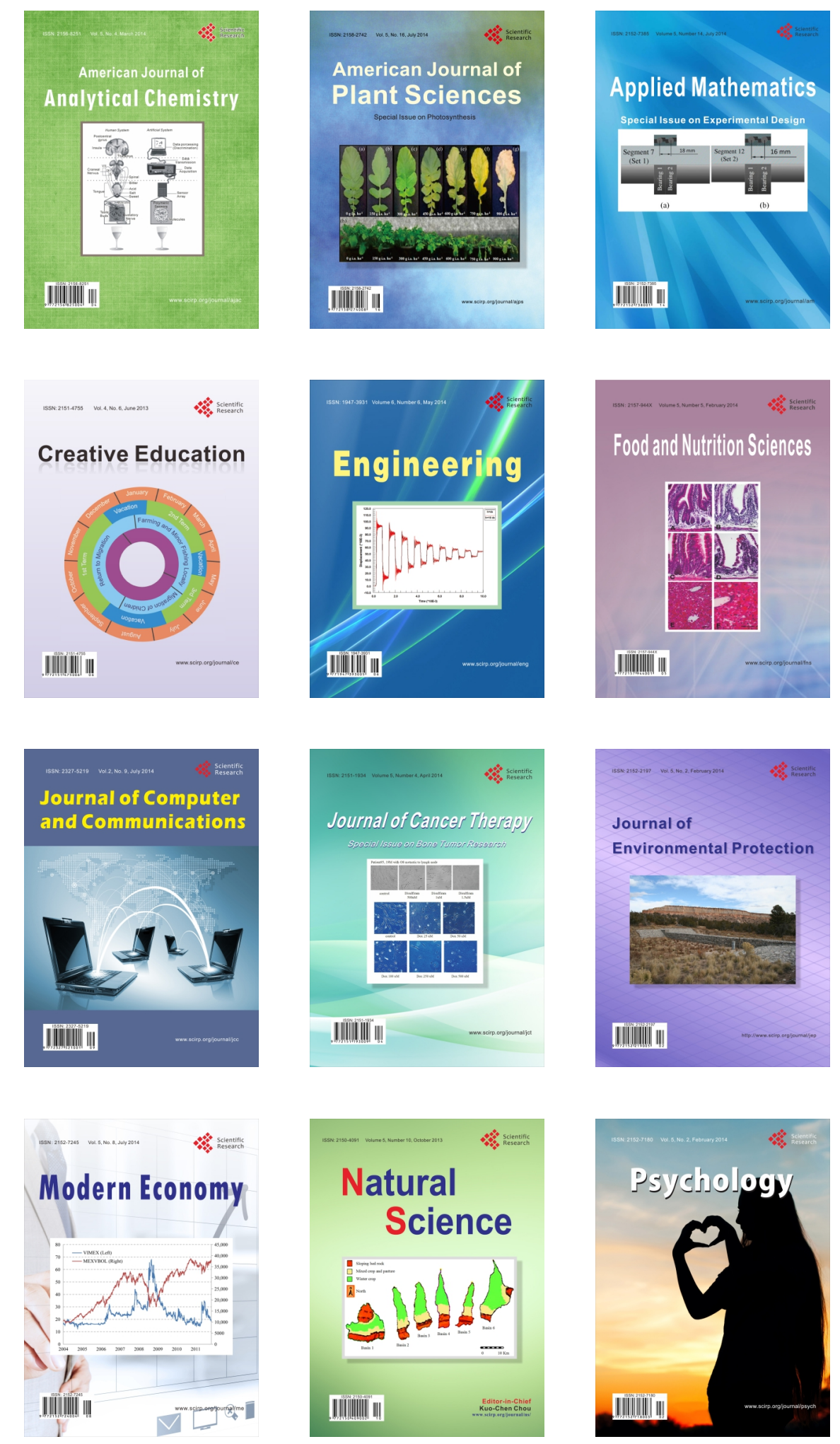